\title{
The Effect of Drying of Bread Wheat Seeds Following First Water Uptake on Germination Rate
}

\author{
Mustafa Yıldırım*
}

Faculty of Agriculture, Kahramanmaraş Sütçü Imam University, 46040 Kahramanmaraş, Turkey

\section{A R T I C L E I N F O}

\section{Research Article}

Received 10 August 2017

Accepted 28 November 2017

Keywords:

Alatav

Germination rate

Time

Wheat

Water uptake \begin{abstract}
A B S T R A C T
In semi-arid regions, unfavorable weather conditions are the most important limiting factors for seed germination. The imbibed or germinating seeds in soil can be dried by hot and dry weather. Thus, seeds can largely lose their germination abilities until the next water uptake (called as 'alatav' in Turkish). Before drying, the time of the first water uptake by a seed may be more effective on seed viability at the second water uptake for germination. Therefore, this experiment was conducted to identify the first water uptake rates (WU) of seeds of three bread wheat genotypes (Bezotaja, Kirac and 13-BVD-4) per hour during 50 hours and their germination rates (GR) at the second water uptake after drying the seeds for 3-week in laboratory conditions. The results presented here indicated that the WU and GR were significantly affected by genotypes, imbibition time (T) and their interaction (1\% probability level). There was also a significant negative correlation between the WU and GR $\left(\mathrm{r}^{* *}=-0.9295\right)$ at all times studied. Furthermore, the germination ability of Kirac lasted longest (for $38^{\text {th }}$ hour) when the WU reached to $160.24 \%$, and it was followed by Bezostaya and 13-BVD-4 genotypes $\left(63.34 \%\right.$ at $37^{\text {th }}$ hour and $152.58 \% 34^{\text {th }}$ hour, respectively).
\end{abstract}

*Corresponding Author:

E-mail: m.yildirim@ksu.edu.tr

DOI: https://doi.org/10.24925/turjaf.v6i1.28-33.1465

\section{Introduction}

Wheat is one of the most consumed cereals (Shewry, 2009; Punter and Pruimboom, 2013) and is widely grown under rain-fed conditions in semi-arid regions of the world (Mathre and Johnston, 1991). In semi-arid regions, water is also one of the most important limiting factors for seed germination (Khayatnezhad et al., 2010; Zaefizadeh et al., 2011; Abdoli and Mohsen, 2012) and early growth stage of wheat (Galle et al., 2007; Ahmad et al., 2009; Almaghrabi, 2012). The sowing time of wheat seed is even more important in a semi-arid climate, where its germination is limited due to erratic rainfall. Because of this reason, wheat seeds are often sown when the soil is too dry (Mathre and Johnston, 1991; Wuest and Lutcher, 2012), or they are sown after rainfall (Yildirim and Dumlupinar, 2014). In the first planting process, when it rains after sowing, water uptake of seeds is started and seeds begin to swell. After the seed imbibition, if there is no rainfall and the weather is dry and hot for a long time, then these conditions may be dry the seeds up in the soil (Eskandari, 2013) and, moreover, these conditions can generally result dry seed decay, caused by some soil funguses (Bateman and Wallace, 1986; Mathre and Johnston, 1991). In the other planting process, when sowing occurs following a rainfall, water uptake of seeds begins in just a few hours after sowing and seeds begin to swell. In the second case, the seeds may be dried by the same conditions as they were in the first process. In the first planting process, there is a possibility for the seeds to remain in the soil for several weeks or months without emerging. To dry the seeds in the soil before or after completing germination, the latter of which is named as 'atalay' in Turkish, is frequently occurred in dry farming areas due to lack of water after initial imbibition (Yildirim and Dumlupinar, 2014). Most dried seeds cannot germinate when the rain falls after a certain amount of time. In Turkey, the same as in most of the world, wheat is grown largely in dry areas and loss in germination abilities of seeds is frequently occurred by erratic rainfall.

Seed germination is one of the most important stages in the life cycle of plants (Khan et al., 2000; Yildirim and Dumlupinar, 2014). There are differences among genotypes in their germination rate in various soil water contents (Bijagare et al., 1994). The water uptake of the seed also depends on the duration of the contact with water. The first two hours of imbibition is very important for seed germination because it is firmly related to the extent of water uptake (King and Richards 1984; Albernethy, 1985; Albernethy et al., 1989: Yildirim and Dumlupinar, 2014). The germination of wheat seeds starts when moisture content of seed reaches approximately $50 \%$ above its dry weight (Ashraf and Abu Shakra, 1978) and it ends after the elongation of the embryo and roots is completed (Bewley, 1997). The longer contact with water, increases swelling of the seed, which subsequently 
accelerates embryo activities. Therefore, rapid water uptake and early germination are disadvantageous for a genotype when alatav occurs.

In scientific literature, several reports about water uptake, imbibition rate, soaking and germination of wheat seeds can be found. However, there is not adequate amount of research that examines the effect of second water uptake after drying of swelled seeds on germination rate at different times. This study was aimed to investigate the effects of imbibition time (during 50 hours) and the genotypes that the seeds had on germination rate after second water uptake of dried seeds at various times and to determine late germinating genotypes which may be an advantage against to alatav risk in semi-arid areas.

\section{Materials and Methods}

A total number of three bread wheat genotypes, (Bezostaya and Kirac varieties and 13-BVD-4 pure-line) were used in this study. Genotypes were provided by Eskisehir Anatolian Agriculture Research Institute (ATAEM) in Turkey. Kernel traits of the genotypes were quite different as shown in Table 1.

The study was made in a randomized complete block factorial design with three replications in a dark room with air conditioning. In each replication, there were 50 groups of seeds for each genotype and each group had 50 seeds. 50 kernels of each group for the initial weight (IW) were weighed before imbibition. 50 seeds of each group were placed on four layers of filter paper placed in petri dishes with a diameter of $5 \mathrm{~cm}$. The Petri dishes were watered with $6 \mathrm{ml}$ of distilled water and covered by plastic paraffin. Then the dishes were incubated in dark room with air conditioning regulated to maintain a constant $25^{\circ} \pm 1^{\circ} \mathrm{C}$ for 50 hours (Caliskan and Cuming, 2000; Harb, 2013). Once an hour, all groups were taken out from dark room and their 50 seeds were dried by paper towel and their final weights $(\mathrm{FW})$ of 50 were determined. WU percentage was calculated by the formula showed below (Kaosa-ard and Songsermpong, 2012; Harb, 2013);

$$
W U_{j}=\frac{\left(F W_{j}-I W_{j}\right)}{I W_{j}} \times 100
$$

Where;

WU : Water uptake (\%),

FW : Final weight $(\mathrm{g})$,

IW : Initial weight $(\mathrm{g})$,

j : Trait per hour.

In order to have them completely dried, the weighed seeds were kept on a paper towel at $25^{\circ} \mathrm{C}\left( \pm 1^{\circ} \mathrm{C}\right)$ with $43 \%$ air humidity for 3 weeks. After 3 weeks, all groups were put on four layers of filter paper in petri dishes and watered and the petri dishes were again. They were covered by plastic paraffin and kept in the same room for 4 days under the conditions described above (Tasc1 and Dinler, 2013). At the end of 4 days, germination counts of groups were performed. The seeds that had coleoptile, radicle and seminal roots were counted as germinated (Figure 1A).

Table 1 The kernel characteristics of three bread wheat genotypes

\begin{tabular}{l|cccccc}
\multicolumn{1}{c|}{ Genotype } & Initial moisture (\%) & 1000 kernel weight $(\mathrm{g})$ & Seed color & Protein $(\%)$ & PSI (\%) & M-SDS (ml) \\
\hline Bezostaya & 10.4 & 50.7 & Red & 10.7 & 59.2 & 34.8 \\
13-BVD-4 & 10.5 & 29.8 & White & 12.6 & 71.5 & 34.3 \\
Kirac & 10.5 & 25.1 & White & 14.0 & 70.6 & 31.1 \\
\hline
\end{tabular}
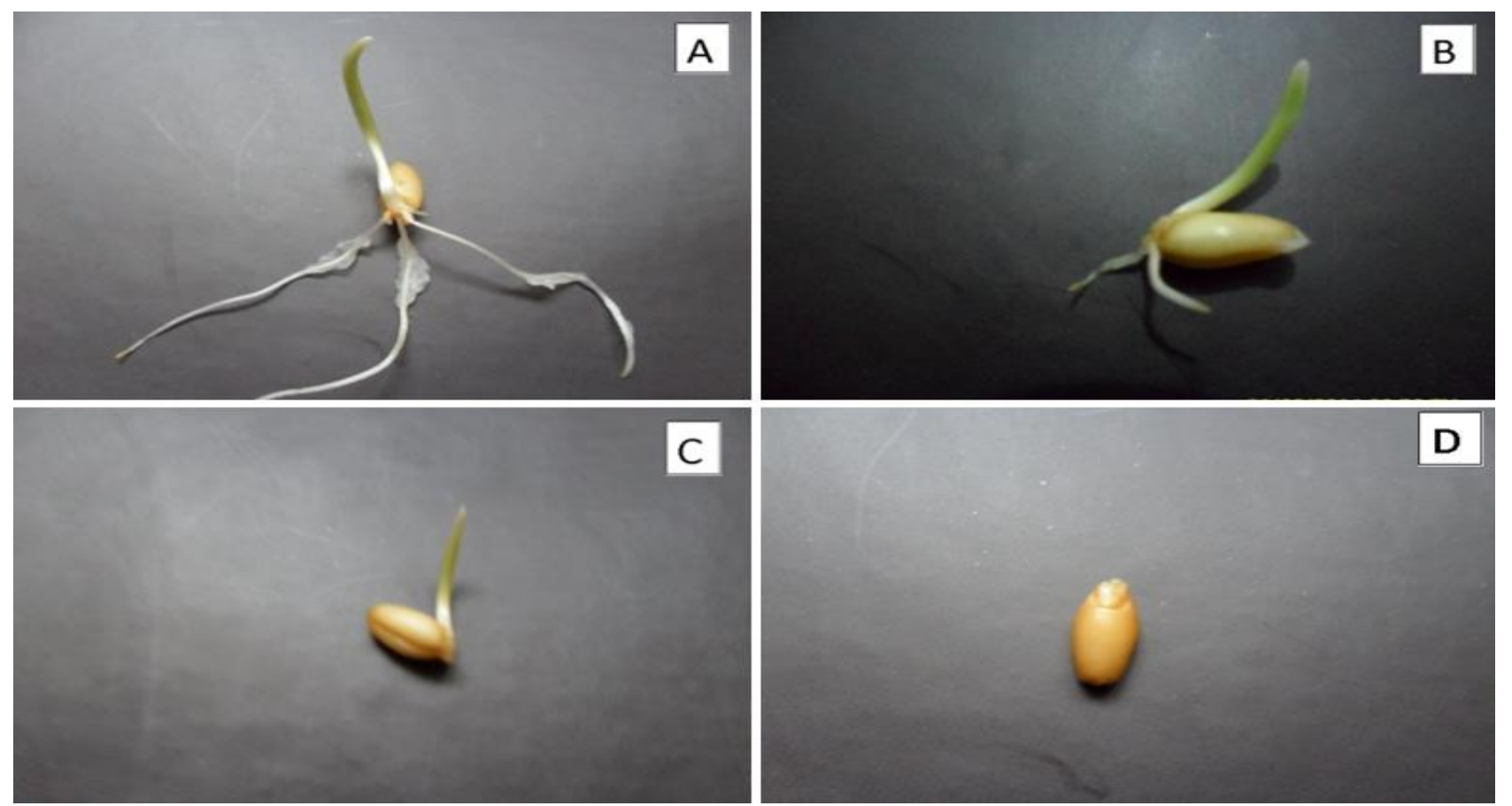

Figure 1 The pictures of germinated (A and B) and non-germinated (C and D) among bread wheat seeds 
In some seeds, the radicle has not observed on germination of second imbibition because it had emerged in the first imbibition and then died. Those seeds had only coleoptile and seminal roots, and so they were also counted as germinated (Figure 1B) If the seeds did not have collectively coleoptiles and seminal roots (Figure 1C) or no one (Figure 1D), they were considered as nongerminated.

In the cases where germination was observed, germination rate (GR) was calculated by following formula;

$$
G R_{j}=\frac{N G_{j}}{50} \times 100
$$

Where,

GR : Germination rate (\%),

NG : Number of germinated seeds,

50 : Number of total seeds.

In a randomized complete block factorial design arrangement with three genotypes, the effects of water uptake time (from 1 to 50 hours) after second imbibition on germination rate were investigated. The collected data were subjected to statistical analysis using MSTAT-C software. When the F-test indicated a statistical significance at $\mathrm{P} \leq 0.01$ or $\mathrm{P} \leq 0.05$ probability levels, mean comparisons were made by LSD

\section{Results}

According to variance analysis shown in Table 2, the investigated traits, final weight (FW), water uptake (WU), number of geminated seeds (NG) and germination rate (GR) were significantly affected by genotypes (G), imbibition times $(\mathrm{T})$ and their interactions $(\mathrm{G} \times \mathrm{T})$ $(\mathrm{P}<0.01)$.

Mean values of three genotypes and imbibition times for IW, FW, WU, NG and GR traits are given in Table 3. The average IW values of 50 seeds for each genotype were calculated as 2.53, 1.49 and $1.26 \mathrm{~g}$ for Bezostaya, 13-BVD-4 and Kirac, respectively. The similar ranking was observed for the mean of FW. The average FW values of imbibition times also changed from $1.86 \mathrm{~g}$ to $3.97 \mathrm{~g}$ at the first and forty-ninth hours, respectively (Table 3). At the first hour, the FW of genotypes reached 2.59, 1.68 and $1.30 \mathrm{~g}$ values for Bezostaya, 13-BVD-4 and Kirac, respectively (Figure 2).
Bezostaya had the lowest mean WU value $(46.46 \%)$ in spite of having the highest IW and FW values. Kirac showed the highest mean WU value (126.02\%) and it was followed by 13-BVD-4 (118.07\%) for this trait. At the first hour, the mean WU was raised to $4.86 \%$ and quickly reached to approximately $50 \%$ after the sixth hour (Table 2). The increase in mean WU values began to slow down between the seventh and the fiftieth hours. After the fortysecond hour, the increase was completely stopped.

The highest GR value was observed in Kirac with (45.25\%) 22.63 germinated seeds and it was followed by Bezostaya (43.91\%) and 13-BVD-4 (37.92\%) with 21.95 and 18.96 germinated seeds, respectively. At the first hour of imbibition, the GR was $99.78 \%$ and began to decrease until thirty-eighth hour $(0.22 \%)$. Starting from the thirtyninth of imbibitions, the seeds began to lose their germination abilities.

According to results, the WU values of genotypes were positively affected by times of imbibition while the GR values were negatively affected by it. The difference between WU and GR, moreover, was significant but negative $\left(\mathrm{r}^{* *}=-0.9295\right)$. There were highly significant variations for WU and GR amongst the genotypes (Figures 3, 4 and 5).

The WU values of genotypes at the first hour were ranged as $7.57 \%, 5.77 \%$ and 2.99 for Kirac, 13-BVD-4 and Bezostaya, respectively. At the third hour, WU values of 13-BVD-4 and Kirac genotypes reached 48.85 and $49.07 \%$ over their dry weights, respectively, while WU value of Bezostaya reached $48.27 \%$ at the twenty-sixth hour (Figure 3).

The GR values of genotypes at the first hour were $99.3 \%$ in 13-BVD-4 and $100 \%$ in Bezostaya and Kirac (Figure 3, 4 and 5). The GR value of Bezostaya at the nineteenth hour was $76 \%$ and it decreased rapidly after that point. The GR value of Bezostaya at the nineteenth hour was $76 \%$ and it showed a quick decrease after that point. The GR value of Kirac was $88 \%$ right before a sharp decline at the eighteenth hour. Of all GR values, Bezostaya showed the most regular decrease.

After the thirty-ninth hour of WU, the germination ability of Kirac genotype was abolished (Figure 4). However, Bezostaya and 13-BVD-4 last germinated at the thirty-eighth and thirty-fifth hours of WU, respectively (Figures 3 and 5).

Table 2 Analysis of variance of final weight (FW), water uptake (WU), number of geminated seeds (NG) and germination rate (GR) of wheat seeds as affected by genotypes $(\mathrm{G})$ and imbibition times $(\mathrm{T})$

\begin{tabular}{l|cccc}
\hline \multicolumn{1}{c}{ Source of variation } & \multirow{2}{*}{ DF } & \multicolumn{3}{c}{ Mean Squares } \\
\cline { 3 - 5 } & & $\mathrm{FW}$ & $\mathrm{WU}$ & $\mathrm{GR}$ \\
\hline Genotypes (G) & 2 & $28.794^{* *}$ & $293202.355^{* *}$ & $2285.785^{* *}$ \\
Imbibition Times (T) & 49 & $2.131^{* *}$ & $8695.423^{* *}$ & $14224.796^{* *}$ \\
$\mathrm{G} \times \mathrm{T}$ & 98 & $0.036^{* *}$ & $539.955^{* *}$ & $71.093^{* *}$ \\
Error & 298 & 0.016 & 97.820 & 30.270 \\
$\mathrm{CV}(\%)$ & & 3.82 & 10.14 & 12.987 \\
\hline
\end{tabular}

\footnotetext{
$* *$ Significant at $1 \%$
} 
Table 3 The mean initial weight (IW), final weight (FW), water uptake (WU), number of geminated seeds (NG) and germination rate (GR) of seeds for genotypes and imbibition times.

\begin{tabular}{|c|c|c|c|c|c|}
\hline Variable & $\mathrm{IW}(\mathrm{g})^{\S}$ & $\mathrm{FW}(\mathrm{g})$ & WU $(\%)$ & $\mathrm{NG}(\mathrm{no})^{\S}$ & GR (\%) \\
\hline \multicolumn{6}{|l|}{ Genotypes (G) } \\
\hline Bezostaya & 2.53 & 3.71 & 46.46 & 21.95 & 43.91 \\
\hline 13-BVD-4 & 1.49 & 3.25 & 118.07 & 18.96 & 37.92 \\
\hline Kirac & 1.26 & 2.84 & 126.02 & 22.63 & 45.25 \\
\hline Mean & 1.76 & 3.27 & 96.85 & 21.18 & 42.36 \\
\hline \multicolumn{6}{|c|}{ Imbibition times $(\mathrm{T})$} \\
\hline 1 & 1.77 & 1.86 & 4.86 & 49.89 & 99.78 \\
\hline 2 & 1.76 & 2.11 & 19.56 & 49.78 & 99.56 \\
\hline 3 & 1.72 & 2.28 & 32.42 & 49.00 & 98.00 \\
\hline 4 & 1.73 & 2.42 & 39.74 & 48.56 & 97.11 \\
\hline 5 & 1.71 & 2.52 & 47.88 & 48.00 & 96.00 \\
\hline 6 & 1.76 & 2.63 & 49.05 & 47.56 & 95.11 \\
\hline 7 & 1.80 & 2.76 & 53.09 & 46.89 & 93.78 \\
\hline 8 & 1.80 & 2.80 & 55.80 & 46.56 & 93.11 \\
\hline 9 & 1.74 & 2.84 & 63.36 & 45.44 & 90.89 \\
\hline 10 & 1.79 & 2.96 & 65.68 & 41.11 & 82.22 \\
\hline 11 & 1.84 & 3.02 & 63.55 & 44.00 & 88.00 \\
\hline 12 & 1.81 & 2.99 & 65.54 & 43.44 & 86.89 \\
\hline 13 & 1.82 & 3.07 & 68.29 & 43.11 & 86.22 \\
\hline 14 & 1.81 & 3.06 & 68.71 & 41.33 & 82.67 \\
\hline 15 & 1.80 & 3.09 & 71.49 & 41.22 & 82.44 \\
\hline 16 & 1.89 & 3.23 & 71.18 & 39.33 & 78.67 \\
\hline 17 & 1.73 & 3.07 & 77.08 & 39.11 & 78.22 \\
\hline 18 & 1.76 & 3.11 & 76.90 & 37.00 & 74.00 \\
\hline 19 & 1.69 & 3.06 & 81.55 & 35.44 & 70.89 \\
\hline 20 & 1.71 & 3.13 & 83.25 & 32.56 & 65.11 \\
\hline 21 & 1.81 & 3.23 & 78.34 & 29.78 & 59.56 \\
\hline 22 & 1.86 & 3.30 & 77.58 & 26.89 & 53.78 \\
\hline 23 & 1.70 & 3.18 & 86.93 & 23.22 & 46.44 \\
\hline 24 & 1.73 & 3.25 & 88.24 & 19.56 & 39.11 \\
\hline 25 & 1.73 & 3.27 & 88.62 & 17.44 & 34.89 \\
\hline 26 & 1.74 & 3.28 & 88.36 & 14.22 & 28.44 \\
\hline 27 & 1.67 & 3.26 & 95.02 & 13.00 & 26.00 \\
\hline 28 & 1.76 & 3.40 & 93.52 & 10.56 & 21.11 \\
\hline 29 & 1.78 & 3.44 & 93.44 & 9.33 & 18.67 \\
\hline 30 & 1.68 & 3.39 & 101.32 & 7.00 & 14.00 \\
\hline 31 & 1.73 & 3.45 & 99.68 & 5.78 & 11.56 \\
\hline 32 & 1.81 & 3.58 & 97.85 & 4.56 & 9.11 \\
\hline 33 & 1.71 & 3.49 & 103.40 & 3.56 & 7.11 \\
\hline 34 & 1.74 & 3.59 & 106.05 & 1.67 & 3.33 \\
\hline 35 & 1.75 & 3.60 & 105.56 & 1.33 & 2.67 \\
\hline 36 & 1.72 & 3.57 & 107.43 & 0.89 & 1.78 \\
\hline 37 & 1.66 & 3.58 & 114.86 & 0.78 & 1.56 \\
\hline 38 & 1.73 & 3.62 & 108.97 & 0.11 & 0.22 \\
\hline 39 & 1.76 & 3.71 & 111.08 & 0 & 0 \\
\hline 40 & 1.75 & 3.73 & 113.02 & 0 & 0 \\
\hline 41 & 1.79 & 3.76 & 109.92 & 0 & 0 \\
\hline 42 & 1.72 & 3.75 & 118.45 & 0 & 0 \\
\hline 43 & 1.75 & 3.77 & 115.56 & 0 & 0 \\
\hline 44 & 1.74 & 3.79 & 117.36 & 0 & 0 \\
\hline 45 & 1.78 & 3.81 & 114.37 & 0 & 0 \\
\hline 46 & 1.76 & 3.83 & 118.20 & 0 & 0 \\
\hline 47 & 1.79 & 3.89 & 117.03 & 0 & 0 \\
\hline 48 & 1.77 & 3.90 & 120.75 & 0 & 0 \\
\hline 49 & 1.88 & 3.97 & 111.85 & 0 & 0 \\
\hline 50 & 1.74 & 3.88 & 123.36 & 0 & 0 \\
\hline Mean & 1.76 & 3.27 & 85.70 & $27.87^{\oplus}$ & $55.74^{\top}$ \\
\hline LSD G & - & $0.04 * *$ & $2.96 * *$ & - & $1.65 * *$ \\
\hline $\mathrm{T}$ & - & $0.15^{* *}$ & $12.09 * *$ & - & $6.72 * *$ \\
\hline $\mathrm{G} \times \mathrm{T}$ & - & $0.26 * *$ & $20.94 * *$ & - & $11.65^{* *}$ \\
\hline
\end{tabular}




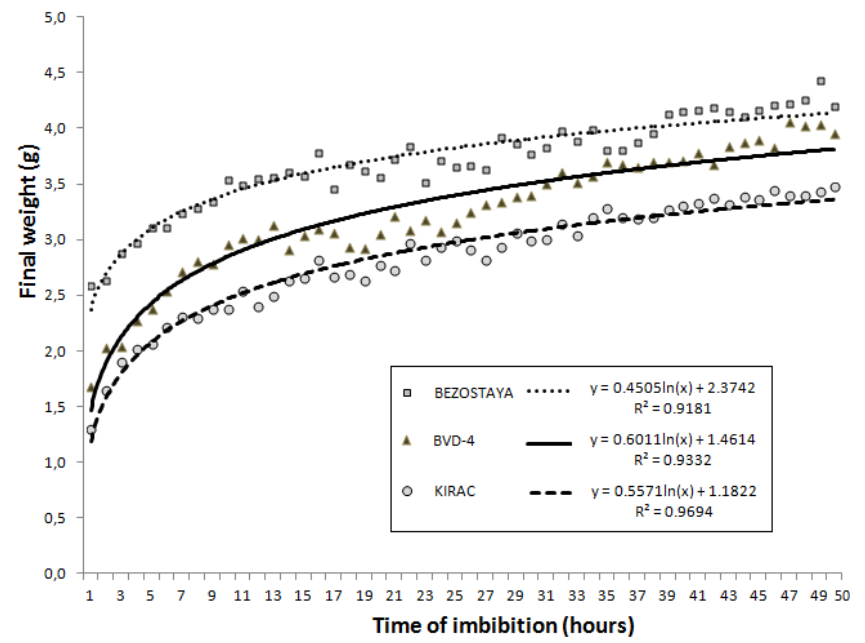

Figure 2 Effect of imbibition times (50 hours) on final weight of genotype seeds

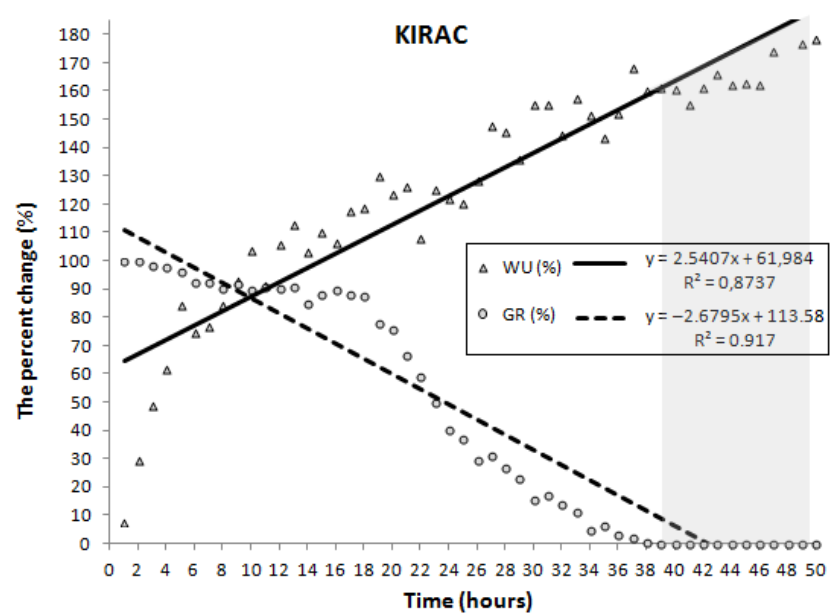

Figure 4 Effect of imbibition times (50 hours) on the percentage changes (\%) of water uptake (WU) and germination rate (GR) in Kirac

\section{Discussions}

Based on the data obtained from the experiments, genotypes, imbibition times and their interactions altered the investigated traits. Final weight of the imbibed kernels differed in each genotype. Kirac increased its FW at the first hour to $167.31 \%$, while Bezostaya at the forty-ninth hour to $71.38 \%$ and $13-\mathrm{BVD}-4$ at the forty-seventh hour to $140.1 \%$. This situation may be explained by different initial weights of the genotypes and their various water uptake potentials due to the genetic influence.

The WU rates of genotypes slowed down after the sixth, eighth and tenth hours (Kirac, Bezostaya and 13BVD-4, respectively). The most significant decline was observed in Bezostaya. At the fiftieth hour, Kirac had the highest WU value (178.14\%) and it was followed by 13BVD-4 and Bezostaya (163 and 71.55\%, respectively). Different water uptake of the genotypes may be due to protein ratio of the kernels related with the thousand kernel weights. It may also be originated from genotypic differences among the genotypes. In previous works; it has been indicated that the water uptake of the seed

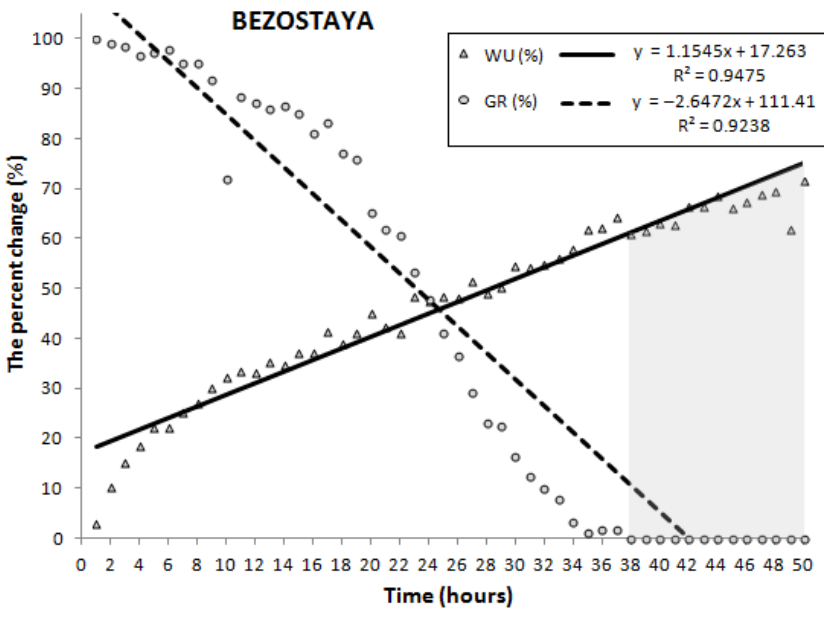

Figure 3 Effect of imbibition times (50 hours) on the percentage changes $(\%)$ of water uptake (WU) and germination rate (GR) in Bezostaya

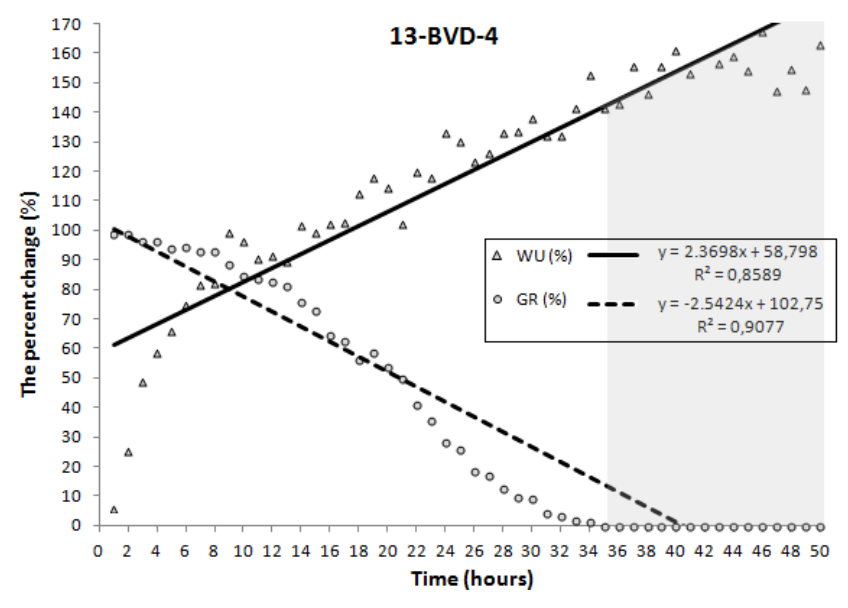

Figure 5 Effect of imbibition times (50 hours) on the percentage changes (\%) of water uptake (WU) and germination rate (GR) in 13-BVD-4

depends on the duration of the contact with water, and the first two hours of imbibition is very important for seed germination because it is highly related to the amount of water uptake (King and Richards 1984; Albernethy, 1985; Albernethy et al., 1989; Li et al., 2013). Wellington (1956) and Huang et al. (1983) also reported that white kernel genotypes has more rapid water uptake compared to red kernel wheat. In addition, King (1984) found that white wheat absorbed more water than red wheat did. Kirac and 13-BVD-4 genotypes are white wheats while Bezostaya genotyope is red. Our findings are in agreement with the previous works.

Germination rate was also one of the most crucial traits for the bread wheat genotypes. The rate of germination was negatively correlated with the imbibition time. It is decreased when imbibition times increased. Early germination triggers alatav conditions due to rapid water uptake. Khan et al. (2000) reported genotypic variation in germination rate at various soil water contents. Additionally, it has also been reported that the 
germination of wheat seed starts when the moisture content of a seed becomes nearly $50 \%$ heavier than its dry weight (Ashraf and Abu Shakra, 1978), and it becomes finalized with the elongation of the embryo and roots (Bewley, 1997). The longer contact with water of seed increases swelling of the seed and accelerates the activities of embryo.

In conclusion, it was observed that the water uptake duration of the genotypes affected the ability of regermination after drying. In addition, there was a negatively and highly significant difference between the WU and GR. This relationship between the GR and WU is a great value in the improvement of our understanding of genotypes' response to alatav. There were differences among genotypes for amount of imbibition at the WU. There also were big differences among genotypes for GR after the second water uptake depending on time at the WU. The white kernel genotypes (Kirac and 13-BVD-4) had more the WU and faster imbibition than red kernel wheat (Bezostaya). Kirac genotype not only had more imbibition compared to others and but it was also more resistance to alatav until the thirty-ninth hour of WU. The results were encouraging for the potential to reduce alatav risk. However, the study should be repeated with several genotypes and parallel studies must be conducted varying in soil conditions for more convincing results.

\section{References}

Abdoli M, Mohsen S. 2012. Effects of water deficiency stress during seed growth on yield and its components, germination and seedling growth parameters of some wheat cultivars. Int. J. Agric. Crop Sci., 15: 1110-1118.

Abernethy RH. 1985. Early induction of heat shock proteins in wheat embryos. Agronomy Abstracts, Madison, WI, pp. 109.

Abernethy RH, Thiel DS, Petersen NS, Helm K. 1989. Thermotolerance is developmentally dependent in germinating wheat seed. Plant Physiol., 89: 596-576.

Ahmad S, R. Ahmad MY, Ashraf M, Waraich EA. 2009. Sunflower (Helianthus annuus L.) response to drought stress at germination and seedling growth stages. Pak. J. Bot., 41:647-54.

Almaghrabi OA. 2012. Impact of drought stress on germination and seedling growth parameters of some wheat cultivars. Life Sci., J 9: 590-598.

Ashraf CM, Shakra AS. 1978. Wheat seed germination under low temperature and moisture stress. Agron. J., 70: 135-139.

Bateman GL. Ehle H, Wallace HA. 1986. Fungicidal treatment of cereal seeds. Pages 83-111 in: Seed treatment. Jeffs KA, ed. BCPC Publications, Thornton Heath, England.

Bau H, Villanme M, Nicolos C, Mejean JPL. 1997. Effect of germination on chemical composition, biochemical constitutes and antinutritional factors of soy bean (Glycine max) seeds. J. Sci. Food Agric., 73: 1-9.

Bewley JD. 1997. Seed Germination and Dormancy. The Plant Cell, 9: 1055-1066.

Bijagare MN, Ghuge SB, Hudge VS. 1994. Effect of moisture stress on seed germination in sorghum. Ann. Plant Physiol., 8: 39-41.

Calıskan M, Cuming AC. 2000. Temporal and spatial determination of germin biosynthesis in wheat tissues. Turk. J. Biol., 24: 775782 .
Eskandari H. 2013. Effects of priming technique on seed germination properties, emergence and field performance of crops: A review. Int. J. Agron. Plant Produc., 4: 454-458.

Galle A, Haldimann P, Feller U. 2007. Photosynthetic performance and water relations in young pubescent oak (Quercus pubescens) trees during drought stress and recovery. New Phytol., 174:799-810.

Harb AM. 2013. Reserve Mobilization, Total Sugars and Proteins in Germinating Seeds of Durum Wheat (Triticum durum Desf.) under Water Deficit after Short Period of Imbibition. Jordan J. Biol. Sci., 6: 67-72.

Huang G, McCrate AJ, Varriano-Marston E, Paulsen GM. 1983. Caryopsis structural and imbibitional characteristics of some hard red and white wheats. Cereal Chem., 60: 161-165.

Kaosa-ard T, Songsermpong S. 2012. Influence of germination time on the GABA content and physical properties of germinated brown rice. Asian J. Food Agro-Industry., 5: 270-283.

Khan MA, Ungar IA, Showalter AM. 2000. Effect of sodium chloride treatments on growth and ion accumulation of the halophyte Haloxylon recurvum. Commun. Soil Sci. Plant Anal., 31: 2763-2774.

Khayatnezhad M, Gholamin R, Jamaati-e-Somarin S, Zabihi-eMahmoodabad R. 2010. Study of water stres effect on wheat genotypes on Germination Indexes. Middle-East J. Sci. Res., 6: 657-660.

King RW. 1984. Water uptake in relation to preharvest sprouting damage in wheat: Grain characteristics. Aust. J. Agric. Res., 36: 337-345.

King RW, Richards RA. 1984. Water uptake in relation to preharvest sprouting damage in wheat: Ear characteristics. Aust. J. Agr. Res., 35: 327-336.

Li H, Li X, Zhang D, Liu H, Guan K. 2013. Effects of drought stress on the seed germination and early seedling growth of the endemic desert plant Eremosparton songoricum (fabaceae). EXCLI J., 12:89-101.

Mathre DE, Johnston RH. 1991. Control if dry seed decay of wheat. Plant Dis., 75: 957-959.

Punder K, Pruimboom L. 2013. The dietary intake of wheat and other cereal grains and their role in inflammation. Nutrients, 5: 771-787.

Shewry PR. 2009. Wheat. J. Exp. Bot., 60: 1537-1553.

Tasc1 EB, Dinler S. 2013. Guano-induced germination and responses of wheat seedlings to guano under water stress treatments. University of Suleyman Demirel, J. Agr. Fac., 8: 44-51.

Wellington PS. 1956. Studies on the germination of cereals. 2. Factors determining the germination behaviour of wheat grains during maturation. Ann Bot 20: 481-500.

Wuest SB, Lutcher LK. 2012. Soil Water Potential Requirement for Germination of Winter Wheat. Soil Sci. Society America J., 77: 279-283.

Yildirim M, Dumlupinar Z. 2014. Effect of Three Weeks of Drying After Terminating Water Uptake at Different Times on Seed Germination in Some Cereals. International Journal of Recent Development in Engineering and Technology, 3 (3): 10-19.

Zaefizadeh M, Jamaati-e-Somarin S. Zabihi-e-Mahmoodabad R, Khayatnezhad M. 2011. Discriminate analyses of the osmotic stress tolerance of different sub-convars of durum wheat during germination. Advan. Environ. Biol., 5: 74-80. 